\title{
Metropolização, homicídios e segurança pública na área metropolitana de Brasília: o município de Águas Lindas de Goiás
}

\author{
Analía Soria Batista, Karla Christina Batista França, \\ Marcelo Berdet \& Marizângela Aparecida de Bortolo Pinto*
}

\begin{abstract}
Resumo: Neste artigo se discute o quadro metropolitano dos homicídios em 2010 em um município do Entorno de Brasília, Águas Lindas de Goiás (GO). As externalidades negativas da metropolização de Brasília, em interface com a estrutura e organização da segurança pública e a fragilidade das ações da assistência social no município, esclarecem a dinâmica dos homicídios e os fatores estruturais que influenciam para a sua ocorrência. A pesquisa baseia-se em dados socioeconômicos secundários e em entrevistas realizadas junto aos atores da segurança pública e da assistência social. Os resultados apontam para a segregação socioespacial e a exclusão social no processo de urbanização do município, o alto grau de interação econômica e social deste último com o Distrito Federal, isto é, a polarização que o Distrito Federal exerce na oferta ao mercado de trabalho e de serviços básicos de educação e saúde. Neste quadro, e em face da alta taxa de homicídios no município, o artigo indica a necessidade de políticas cooperadas entre os diferentes entes da Federação envolvidos (União, estados, Distrito Federal e municípios) na área econômica e social e das políticas de segurança pública.
\end{abstract}

Palavras-chave: metropolização, segurança pública, homicídio, segregação socioespacial.

\section{Introdução}

$\square$

ste texto reflete sobre uma parte do trabalho Gestão da segurança pública e metropolização: A Região Integrada de Desenvolvimento do Distrito Federal e Entorno (Ride-DF). Relatório de pesquisa ${ }^{1}$ (Soria Batista et alii, 2013). O relatório integra uma pesquisa mais ampla - Avaliação dos homicídios na Ride-DF -, realizada em 2013 por uma equipe de pesquisadores do Núcleo de Estudos sobre Violência e Segurança da Universidade de Brasília (Nevis/UnB), para a Secretaria Nacional de Segurança Pública (Senasp), que resultou no diagnóstico dos homicídios nos municípios do Entorno do Distrito Federal durante o ano de 2010.

A pesquisa partiu do levantamento do quadro dos homicídios em três municípios da Área Metropolitana de Brasília, quais sejam: Águas Lindas de Goiás, Luziânia e Valparaíso de Goiás, que apresentaram as maiores taxas de homicídios entre os municípios da Área Metropolitana durante o ano de 2010. Propõe-se, aqui, discutir este retrato para a compreensão dos homicídios especificamente no município de
Recebido: 12.10 .14

Aprovado: 06.12.15
* Analía Soria

Batista, professora adjunta do Departamento de Sociologia, Universidade de Brasília, pesquisadora do Núcleo de Estudos sobre Violência e Segurança (Nevis).

<analiasoria@unb. br>. Karla Christina Batista França, geógrafa, doutora em geografia pelo PPGEA-UnB.

<karla.cidades@ gmail.com>. Marcelo Berdet, doutor em sociologia do Programa de Pós-Graduação em Sociologia do Departamento de Sociologia da Universidade de Brasília, pesquisador do Núcleo de Estudos sobre Violência e Segurança (Nevis). <mberdet@ yahoo.com. br>. Marizângela Aparecida de Bortolo Pinto, professora do Instituto Federal de Goiás Campus Luziânia, pesquisadora do Núcleo de Estudos e Pesquisas Educação, Sociedade e Trabalho (Nepest/ IFG), doutoranda em geografia pela Universidade de Brasília. $<$ marizangela. bortolo@ifg.edu.br>. 
1. Importa esclarecer que o estudo parte de um recorte institucional, a Ride-DF, logo, há especificidades em tal delimitação, por exemplo: a escolha do recorte espacial não apresenta coesão do ponto de vista institucional para o reconhecimento de uma região metropolitana no Brasil. O recorte da Ride-DF não apresenta similaridade com a realidade dos processos metropolitanos que se constituem, ou seja, o fenômeno metropolitano está presente na articulação de um conjunto de municípios goianos com a capital federal - Brasília. Portanto, a escala metropolitana que denominamos, por ora, Área Metropolitana de Brasília (AMB), não existe institucionalmente, mas pauta a agenda de articulação política, econômica e de planejamento urbano do Distrito Federal e do Governo do Estado de Goiás e é reconhecida pela Companhia de Planejamento do Distrito Federal (Codeplan).

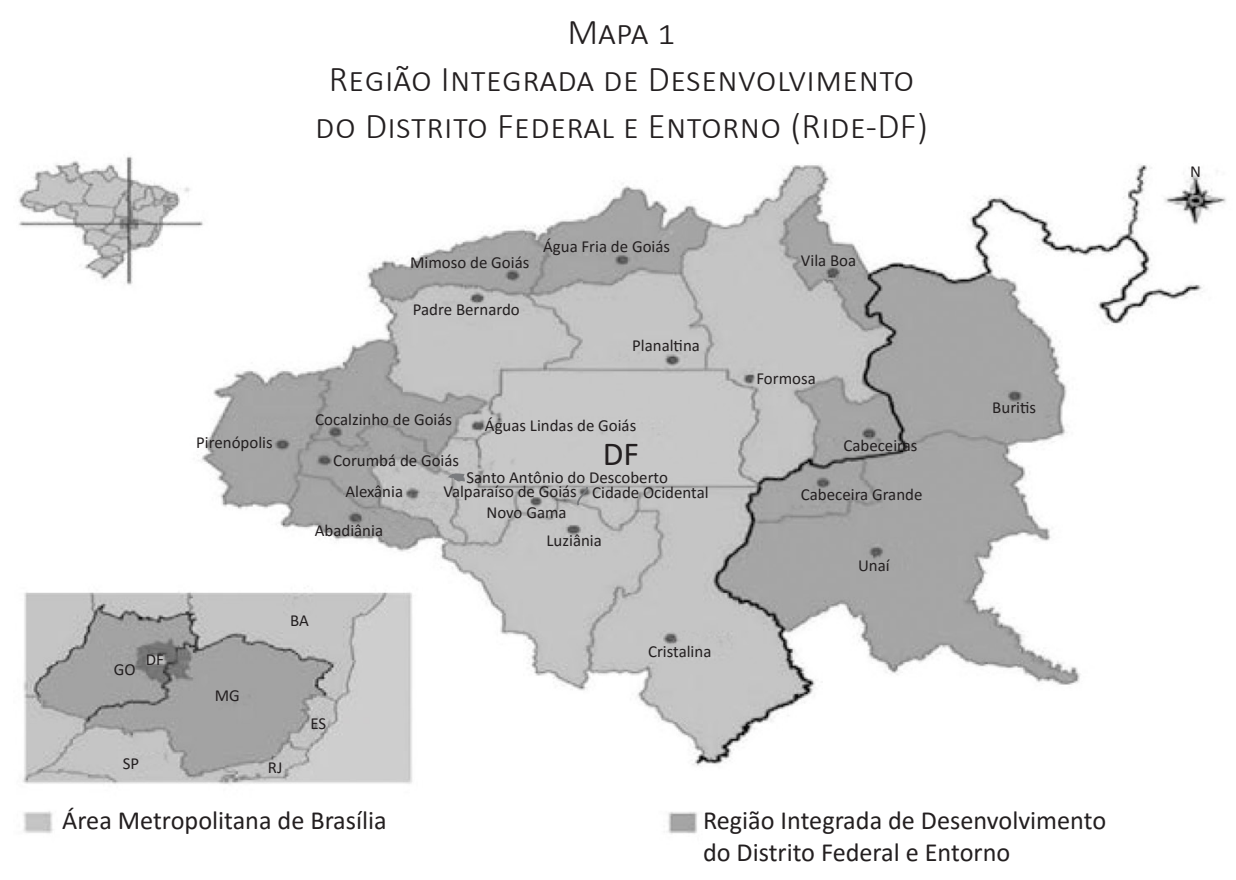

Águas Lindas de Goiás, considerando as influências do processo de metropolização de Brasília no município, sua dependência em relação ao mercado de trabalho e acesso aos serviços básicos como saúde e educação.

O levantamento em relação à estrutura espacial do município considera as características específicas de sua urbanização, o aumento populacional devido às migrações intrametropolitanas e de outros estados da Federação, em interface com a estrutura e organização da segurança pública e da assistência social.

O município de Águas Lindas de Goiás apresentou, em 2010, elevadas taxas de homicídios distribuídos em bairros de formação recente na área urbana e constitui um território socialmente vulnerável. A pobreza urbana não é o único fator na compreensão dos homicídios, mas constitui um dos elementos a ser considerado nas análises que procuram esclarecê-los. A análise aqui apresentada não busca abordar as causas tópicas e específicas dos homicídios no município, mas contextualizar essas ocorrências e discutir suas dinâmicas a partir da análise de aspectos estruturais, como o processo de metropolização de Brasília e suas externalidades negativas, na forma da segregação socioespacial, da pobreza e das migrações enquanto aspectos que influenciam a criminalidade.

Considerar a influência de aspectos estruturais como os mencionados na ocorrência da criminalidade não é algo novo; essas relações já tinham sido apontadas por Boris 
Fausto (1984) em estudo considerado clássico sobre a criminalidade e os crimes na cidade de São Paulo entre os anos 1880 e 1924, no contexto da industrialização e da urbanização dessa cidade.

Ao contrário das teorias centradas em "perfis das vítimas" do homicídio, este artigo centra-se nos efeitos do "perfil do lugar" - especificamente na criação, organização ou ausência de condições favoráveis ou desfavoráveis à criminalidade e delinquência. A baixa organização social refere-se à incapacidade de uma comunidade para resolver problemas crônicos. Por essa perspectiva, a pobreza, a mobilidade residencial, a heterogeneidade com relação à origem e as redes sociais fragilizadas diminuem a capacidade de uma comunidade para controlar o comportamento considerado antissocial e criminoso.

O artigo é sistematizado em cinco seções e conclusão. A primeira apresenta os procedimentos metodológicos da pesquisa; a segunda discute as relações entre os processos de metropolização das cidades e as estratégias de gestão da segurança pública; na sequência, a terceira focaliza aspectos socioeconômicos e a urbanização do município de Águas Lindas de Goiás; a quarta exibe dados sobre os homicídios em 2010 e discute suas dinâmicas; a quinta analisa aspectos da estrutura e da organização da segurança pública e da assistência social no município. As conclusões apontam para a complexidade da gestão da segurança pública em territórios metropolitanos, indicando caminhos possíveis para a melhoria dessa gestão.

\section{Metodologia}

Indicamos aqui a metodologia geral utilizada no estudo Gestão da segurança pública e metropolização: A Região Integrada de Desenvolvimento do Distrito Federal e Entorno (Ride-DF), que possibilitou realizar o presente artigo, como apontado acima. A pesquisa faz uso de levantamento, processamento, tratamento e análise de dados secundários e da aplicação de dez entrevistas semiestruturadas com atores da segurança pública (cinco) e da assistência social (cinco). As entrevistas foram realizadas nas seguintes instituições: Centro Integrado de Segurança Pública, Delegacia Regional do Entorno, Diretoria do Instituto Médico Legal (IML) do Entorno Sul e Secretarias Municipais de Assistência Social (Secretarias de Ação Social), ao longo do ano de 2013.

Utilizaram-se informações estatísticas com base nos dados do Instituto Brasileiro de Geografia e Estatística (IBGE), do Instituto de Pesquisa Econômica Aplicada (Ipea) e de órgãos de planejamento estaduais das unidades federativas de Goiás e do Distrito Federal. O tratamento dos dados permitiu utilizar um leque de indicadores necessários à realização da caracterização socioeconômica da Ride-DF. Assim, o critério empregado na caracterização socioeconômica dos municípios exigiu a seleção dos 
indicadores disponíveis, ao mesmo tempo em que foram feitos todos os esforços possíveis à estruturação do tema, para se obter uma maior aproximação com a realidade da Ride-DF e dos municípios que a integram, nas esferas social e econômica.

A metodologia empregada buscou desenhar o processo de urbanização das cidades que integram a AMB. O estudo analisou os seguintes indicadores: população residente, taxas de homicídio por 100 mil habitantes, indicadores de emprego e trabaIho, atividade econômica, educação, condições de moradia, produto interno bruto (PIB) e renda, estrutura da segurança pública e assistência social.

\section{Metropolização e segurança pública}

Na América Latina, os processos de metropolização e de expansão do tecido urbano se relacionam com o fenômeno da periferização, isto é, processos de expansão da franja urbana por moradias de baixa renda e ocupação urbana descontínua e com deficiências de infraestrutura e baixo grau de coesão ou participação social na estruturação das regiões metropolitanas (Sposito, 2004). As periferias das metrópoles de América Latina são marcadas pela precarização de serviços urbanos e pela ineficiência de políticas públicas, configurando um território de tensões e conflitos. Pode-se pensar a criminalidade violenta como conjunto de processos sociais em interface com a dinâmica urbana, por meio da abordagem denominada socioecológica. Essa abordagem envolve os processos de socialização de grupos, seus aspectos formais e informais, a habilidade ou inabilidade das estruturas de governo em garantir com qualidade a oferta e o acesso das comunidades locais aos serviços públicos. Tal abordagem relaciona a espacialização geográfica da criminalidade e a dinâmica socioespacial (Shaw e McKay, 1972).

A maior parte das cidades apresenta, em graus distintos, problemáticas urbanas, como falta de segurança pública, inadequação da habitação, inadequação nos serviços de saneamento básico, precária oferta do transporte urbano etc. Para Luciana Andrade e Antônio Marinho (2013), a incongruência entre o processo de metropolização que concentra desigualmente a riqueza e o desenvolvimento humano nas metrópoles também reproduz a pobreza, as privações, os conflitos e as formas de organização da vida social mais vulneráveis às situações de violência e criminalidade. A criminalidade seria explicada pelas interações socioespaciais e construções políticas, até mesmo pela formulação de políticas públicas para o enfrentamento da violência e da criminalidade nos territórios metropolitanos.

O estudo das taxas de homicídios em interface com a questão metropolitana requer a compreensão da reconfiguração dos processos de urbanização recente no país. Antônio Marinho e Leandro Basegio asseveram: 
As transformações históricas e as diversas formas de territorialização dos conflitos sociais são relevantes na compreensão da violência, considerados a partir do modo como o espaço tem sido apropriado pelos diversos grupos a partir das disputas, tensões e interações sociais (Marinho \& Basegio, 2013: 98).

O esforço em analisar o fenômeno dos homicídios no Brasil perpassa a questão metropolitana. Seria então razoável sugerir que há maior possibilidade de consumação de um homicídio em territórios de elevada desigualdade social, escassez de recursos públicos e baixa eficácia ou completa ineficácia da ação de agentes públicos. Os estudos no Brasil que procuram investigar as taxas de homicídios em contexto urbano revelam a relação com os processos de segregação socioespacial e a ausência ou oferta inadequada dos serviços públicos na periferia das metrópoles (Abramoway, 2002; Cruz et alii, 2007; Waiselfisz, 2008). Tais territórios são marcados pela disputa por bens materiais, com hegemonia do tráfico de drogas, dos conflitos intersubjetivos e simbólicos e da resolução de conflitos interpessoais pela força (Morenoff, Sampson \& Raudenbush, 2001).

Estudo realizado por Paula Miraglia (2010), em bairro periférico de São Paulo - caracterizado pela elevada taxa de homicídios praticados entre os jovens -, apontou para a presença de uma sociabilidade violenta. Nas palavras da autora,

\begin{abstract}
em cada interação, as relações de poder são redefinidas e renegociadas, tendo como pano de fundo a possibilidade de matar e morrer. Está indicada aí, pois, a construção de um novo tipo de sociabilidade onde a morte não só é tolerada, mas é um desfecho possível e legítimo para conflitos do cotidiano (Miraglia, 2010: 284).
\end{abstract}

Segundo dados do Censo de 2010, 43,91\% da população brasileira vive em municípios integrantes de regiões metropolitanas. Os dados da Pesquisa do Produto Interno Bruto municipal realizada pelo IBGE (2010), no período de 2005-2009, revelaram que $25 \%$ da riqueza produtiva estava concentrada em apenas cinco cidades-capitais: "São Paulo (SP), 12,0\%; Rio de Janeiro (RJ), 5,4\%; Brasília (DF), 4,1\%; Curitiba (PR), 1,4\%; e Belo Horizonte (MG), 1,4\%". Ademais, a pesquisa ressaltou, ao excluir as cidades-capitais, que apenas

[...] doze municípios se destacaram por gerarem individualmente mais do que $0,5 \%$ do PIB, contribuindo com 9,3\% da renda gerada no país. São eles: Guarulhos (SP), 1,0\%; Campinas (SP), 1,0\%; Osasco (SP), 1,0\%; São Bernardo do Campo (SP), 0,9\%; Barueri (SP), $0,8 \%$; Duque de Caxias (RJ), 0,8\%; Betim (MG), 0,8\%; Santos (SP) e São José dos Campos (SP), ambos com 0,7\%; Campos dos Goytacazes (RJ), 0,6\%; e Jundiaí (SP) e Canoas (RS), ambos com 0,5\% (IBGE, 2010: 21). 
2. A Fundação João Pinheiro, responsável pelo levantamento do déficit habitacional no Brasil, conceitua-o da seguinte forma:

"O conceito de déficit habitacional utilizado está ligado diretamente às deficiências do estoque de moradias. Engloba aquelas sem condições de serem habitadas em razão da precariedade das construções e que, por isso, devem ser repostas. Inclui ainda a necessidade de incremento do estoque, em função da coabitação familiar forçada (famílias que pretendem constituir um domicílio unifamiliar), dos moradores de baixa renda com dificuldades de pagar aluguel e dos que vivem em casas e apartamentos alugados com grande densidade. Inclui-se ainda nessa rubrica a moradia em imóveis e locais com fins não residenciais. 0 déficit habitacional pode ser entendido, portanto, como déficit por reposição de estoque e déficit por incremento de estoque" ( Fundação João Pinheiro, 2013: 13).
A pesquisa evidenciou o poder de polarização das regiões metropolitanas na produção nacional. Revelou o quão concentrado é o PIB em determinados municípios das regiões metropolitanas (RMs). Em paralelo ao poder de fluidez econômica, as RMs também concentram os mais elevados índices de precariedade urbana. Estima-se, com base em estudos realizados pela Fundação João Pinheiro (FJP), em parceria com o Ministério das Cidades, que o déficit habitacional ${ }^{2}$ brasileiro calculado com base no Censo de 2010 apresentava, naquele ano, uma carência de seis milhões e 940 mil unidades. Deste total, 85\% estavam em áreas urbanas e 15\% em áreas rurais. No período avaliado, o déficit habitacional urbano relativo às regiões metropolitanas foi estimado, em termos absolutos, em 3,299 milhões unidades. Ao considerar o estudo da Fundação João Pinheiro, a Ride-DF apresenta o quarto maior déficit habitacional absoluto do país, na ordem de 166 mil unidades em comparação com as RMs de São Paulo (793 mil unidades), Rio de Janeiro (387 mil unidades), Belo Horizonte (167 mil unidades) (FJP, 2013).

Em relação às taxas de homicídios em contexto metropolitano, foram considerados os dados da pesquisa "Mapa da violência-2013" (Waiselfisz, 2013). A situação homicida nas regiões metropolitanas se apresentava em trajetória ascendente e concentrada entre os anos de 1980-1996. Desde então os dados revelam redução e estagnação dos homicídios no conjunto das RMs, embora existam oscilações e sua distribuição não seja homogênea no espaço urbano.

A queda das taxas de homicídios tem efeitos positivos nas RMs, dada a complexidade da reprodução das relações sociais. Luciana Andrade e Antônio Marinho (2011) alertam que, embora exista uma queda, ainda assim é grave a concentração da taxa de homicídios por grupo de 100 mil habitantes em RMs. Para fins de exemplificação, no ano de 2007, 45\% das taxas de homicídios estavam concentradas em apenas dez RMs.

Na série de estudos denominada Mapa da violência (Waiselfisz, 2002; 2008; 2013), consta-se que na última década tem sido recorrente a tese da interiorização dos homicídios, no momento em que as pesquisas revelaram uma redução significativa das taxas de homicídios nas RMs, especialmente as de São Paulo e Rio de Janeiro. Para Andrade e Marinho (2011) a elevação dos homicídios em cidades não abarcadas nas regiões metropolitanas e capitais não deve ser analisada de forma dicotomizada, como se os processos espaciais não apresentassem correlação com a dinâmica da urbanização e a desconcentração das atividades econômicas em áreas de influência das RMs. Para os autores, a dimensão urbana e os complexos processos de urbanização recentes no Brasil reposicionaram nossas regiões metropolitanas e sua capacidade de atração e polarização na rede urbana. 
Logo, a expansão urbana dos homicídios, classificados no Mapa da violência como possível interiorização da violência, requer análises aprofundadas e integradas com os processos de urbanização recentes (Waiselfisz, 2002, 2008, 2013). No Brasil, a criminalidade homicida mantém um padrão metropolitano e forte territorialização, contrariando o fenômeno e a classificação de "interiorização da violência", embora a territorialização dos homicídios apresente distintos padrões no conjunto das RMs e tem revelado que os municípios com alto grau de integração com a área-polo absorvem os problemas urbanos do município-polo (Andrade \& Marinho, 2013). Sabe-se que os homicídios não se distribuem uniformemente no território, por isso é importante a verificação dos graus de integração, polarização dos municípios no conjunto da RM entre os municípios e o município-polo da RM.

A questão fundamental, do ponto de vista do interesse das políticas sociais e de segurança é que a escala dos problemas urbanos em territórios metropolitanos transcende os limites administrativos e, assim, necessita de estratégias concertadas entre os diferentes entes da Federação e os agentes quando os serviços se configuram como funções públicas de interesse comum. Isso significa que os serviços urbanos com importante relação com outros municípios devem ser planejados de forma coordenada.

Daí o reconhecimento de que alguns serviços urbanos podem ser caracterizados como "funções públicas de interesse comum", a depender da sua espacialização no território (Moura \& Gorsdorf, 2011). De outro lado, as estratégias implementadas de forma desintegrada por um município metropolitano, isto é, as soluções equacionadas de forma ineficiente na escala local, sem a cooperação dos demais municípios, podem gerar impactos negativos, na medida em que as novas configurações urbanas se convertem em enormes desafios para a gestão e o planejamento que perpassam o tecido metropolitano.

A seguir, caracterizaremos os pontos de vista socioeconômico e o processo de urbanização do município de Águas Lindas de Goiás.

\section{Águas Lindas de Goiás:}

\section{aspectos socioeconômicos e processo de urbanização}

Águas Lindas de Goiás é o segundo município mais populoso da Ride-DF. Conta com uma população de 159.378 habitantes, densidade demográfica elevada de aproximadamente $846 \mathrm{~h} / \mathrm{km}^{2}$. O crescimento na última década foi expressivo, cerca de $4 \%$, acima da média nacional e da região Centro-Oeste, que foi uma das que mais cresceram nos últimos anos, com 1,91\% (Censo/IBGE, 2010). 
O incremento na população na última década atingiu aproximadamente 54 mil habitantes redefinindo a malha urbana do município e expandindo a área urbana sobre a rural, sobretudo com o acelerado processo de loteamentos irregulares para a população de menor renda.

A economia do município é marcada pelo setor de serviços que equivale a $43,4 \%$ do PIB, com destaque para o setor de confecção de artigos de vestuário e acessórios. Em relação ao nível de dependência dos serviços relacionados à administração pública, observa-se que 40,2\% do PIB municipal vincula-se diretamente ao poder público, com a participação de órgãos municipais e estaduais. No Mapa 2, observa-se a distribuição da população e sua renda, com destaque para a renda média mensal de até dois salários mínimos (Censo, 2010).

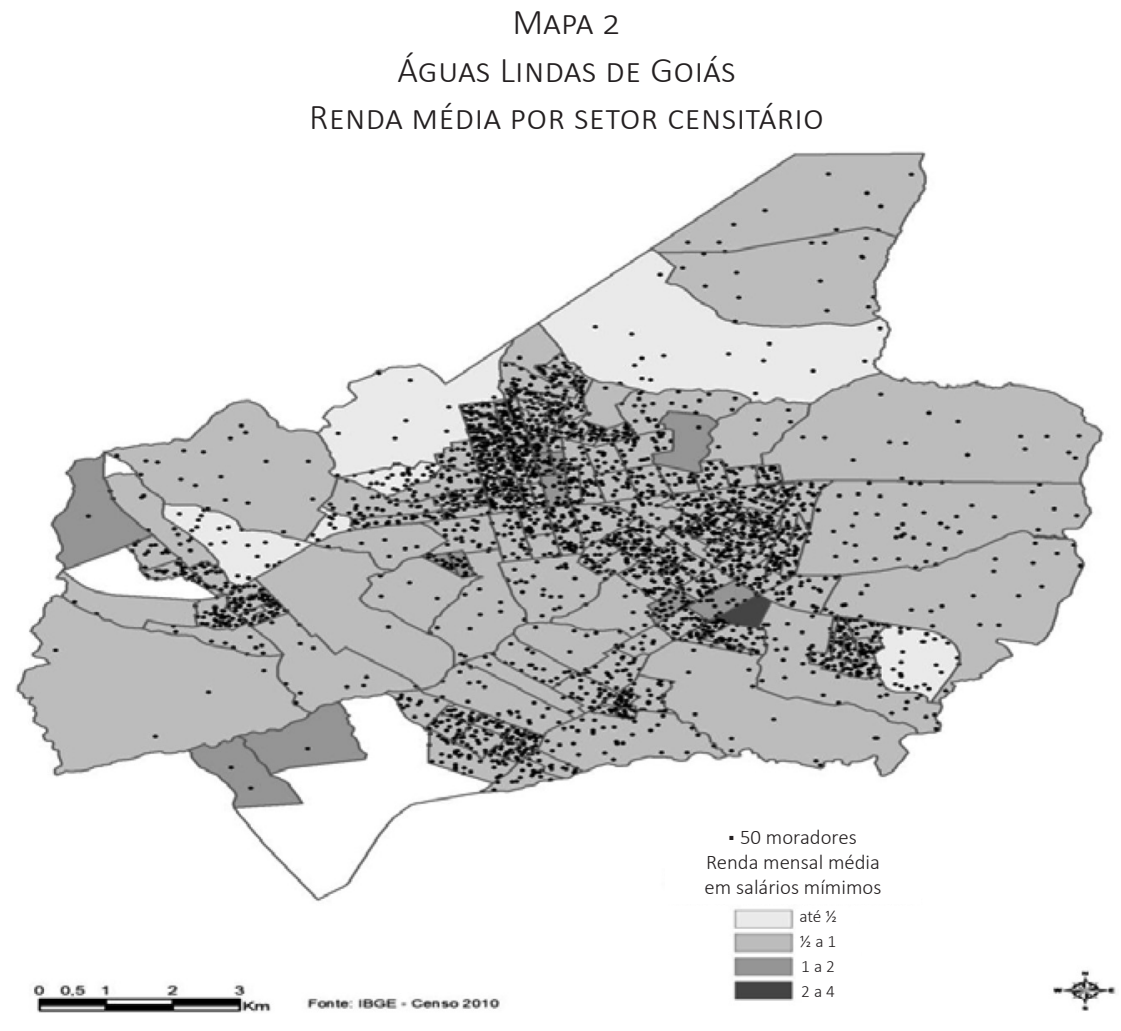

O índice de desenvolvimento humano (IDH) do município encontra-se entre os menores da Ride-DF. Na última década, contudo, o município saiu de 0,387 para o ano de 1991 - índice considerado muito baixo para o nível médio, para 0,686 em 2010, o que representa a 2.282a posição entre os municípios brasileiros e a $152^{\mathfrak{a}}$ posição no estado de Goiás. O maior crescimento no IDH naquele período refere-se à educação, que registrou variação de 360\% entre 1991 e 2010 (Atlas DH, 2013). 
TABELA 1

IDH DOS MUNICÍPIOS DO ENTORNO DO DISTRITO FEDERAL

\begin{tabular}{|c|c|c|c|c|c|c|c|c|c|c|c|c|}
\hline \multirow{2}{*}{$\begin{array}{l}\text { Municípios da área metro- } \\
\text { politana de Brasília (AMB) }\end{array}$} & \multicolumn{3}{|c|}{ IDHM } & \multicolumn{3}{|c|}{ IDHM Educação } & \multicolumn{3}{|c|}{ IDHM Longevidade } & \multicolumn{3}{|c|}{ IDHM Renda } \\
\hline & 1991 & 2000 & 2010 & 1991 & 2000 & 2010 & 1991 & 2000 & 2010 & 1991 & 2000 & 2010 \\
\hline Distrito Federal & 0,616 & 0,725 & 0,824 & 0,419 & 0,582 & 0,742 & 0,731 & 0,814 & 0,873 & 0,762 & 0,805 & 0,863 \\
\hline Valparaíso de Goiás & 0,531 & 0,632 & 0,746 & 0,331 & 0,474 & 0,695 & 0,687 & 0,776 & 0,815 & 0,660 & 0,686 & 0,733 \\
\hline Formosa & 0,482 & 0,598 & 0,744 & 0,259 & 0,422 & 0,666 & 0,684 & 0,776 & 0,852 & 0,631 & 0,653 & 0,726 \\
\hline Cidade Ocidental & 0,538 & 0,638 & 0,717 & 0,338 & 0,486 & 0,641 & 0,710 & 0,797 & 0,814 & 0,650 & 0,670 & 0,706 \\
\hline Luziânia & 0,43 & 0,550 & 0,701 & 0,195 & 0,334 & 0,602 & 0,665 & 0,779 & 0,831 & 0,614 & 0,639 & 0,689 \\
\hline Cristalina & 0,474 & 0,578 & 0,699 & 0,260 & 0,380 & 0,587 & 0,699 & 0,786 & 0,814 & 0,586 & 0,646 & 0,716 \\
\hline Águas Lindas c & 0,387 & 0,497 & 0,686 & 0,145 & 0,277 & 0,588 & 0,667 & 0,762 & 0,848 & 0,600 & 0,583 & 0,647 \\
\hline Novo Gama & 0,451 & 0,546 & 0,684 & 0,235 & 0,357 & 0,567 & 0,661 & 0,735 & 0,851 & 0,589 & 0,619 & 0,664 \\
\hline Alexânia & 0,378 & 0,520 & 0,682 & 0,158 & 0,318 & 0,568 & 0,647 & 0,735 & 0,841 & 0,529 & 0,600 & 0,664 \\
\hline Planaltina & 0,384 & 0,508 & 0,669 & 0,156 & 0,286 & 0,566 & 0,657 & 0,760 & 0,810 & 0,554 & 0,602 & 0,653 \\
\hline Sto. Antônio do Descoberto & 0,409 & 0,526 & 0,665 & 0,183 & 0,334 & 0,556 & 0,669 & 0,755 & 0,818 & 0,559 & 0,576 & 0,647 \\
\hline Cocalzinho de Goiás & 0,363 & 0,506 & 0,657 & 0,138 & 0,310 & 0,531 & 0,632 & 0,735 & 0,826 & 0,547 & 0,567 & 0,648 \\
\hline Padre Bernardo & 0,346 & 0,484 & 0,651 & 0,124 & 0,261 & 0,515 & 0,648 & 0,728 & 0,801 & 0,517 & 0,598 & 0,670 \\
\hline
\end{tabular}

Apesar da melhoria nos indicadores de educação, não é possível dizer que houve alteração do quadro de analfabetismo e da qualificação da mão de obra da população. Nesse sentido, reforça-se o cenário de vulnerabilidade social a que está exposta especialmente a juventude masculina. Do ponto de vista dos indicadores educacionais, a cidade não destoa da realidade observada nos demais municípios da área metropolitana de Brasília, condição que reforça a lógica de dependência da população com a oferta de serviços pouco remunerados.

Esses dados permitem compreender o contexto socioeconômico e a realidade de uma cidade dormitório da periferia do Distrito Federal, que tem crescido rapidamente na última década e que é marcada pelo alto nível de dependência da rede de serviços e oferta de emprego do Distrito Federal. Cerca de 43.799 mil pessoas se deslocam diariamente para trabalhar ou estudar no Distrito Federal, número que corresponde a $27,5 \%$ da população, que diariamente participa do movimento pendular metropolitano. Quando selecionada, a população que declarou trabalhar no Distrito Federal, esse dado chega a 30.859 habitantes, em sua maioria pessoas que ocupam funções que exigem baixa qualificação profissional e com baixa remuneração (Segplan/IMB, 2012).

Um aspecto importante quanto à ocupação da população que participa do movimento pendular é apresentado pela pesquisa de Amostra de Domicílio realizada pelo Censo (2010), considerando o seu nível de instrução. A pesquisa levantou que 
3. É o percentual de pessoas ocupadas na semana de referência em relação às pessoas em idade de trabalhar: Pessoas ocupadas - são classificadas como ocupadas na semana de referência as pessoas que, nesse período, trabalharam pelo menos uma hora completa em trabalho remunerado em dinheiro, produtos, mercadorias ou benefícios (moradia, alimentação, roupas, treinamento etc.) ou em trabalho sem remuneração direta em ajuda à atividade econômica de membro do domicílio ou, ainda, as pessoas que tinham trabalho remunerado do qual estavam temporariamente afastadas nessa semana.
60,05\% das pessoas nos domicílios visitados em Águas Lindas de Goiás se declararam sem instrução ou com ensino fundamental incompleto. Os entrevistados que declararam possuir o nível médio incompleto chegam a 18,99\%, proporção muito próxima do grupo que declarou possuir o ensino médio completo ou superior incompleto, que corresponde a 19,06\%.

Quando considerados os dados referentes à educação básica no município, de acordo com o Censo de 2010 são cerca de cinco mil matrículas no ensino médio que contemplam apenas $10 \%$ da população jovem local, fato que indica a condição de vulnerabilidade de um elevado número de jovens fora da escola, ou que estudam fora da cidade.

A questão a ser considerada não é o tipo de qualificação ou a renda do trabalho como fatores estruturantes da violência homicida, mas o fato de que em tempo de elevada competitividade, o nível de empregabilidade de uma população está solidamente correlacionado à qualificação. Ao partir desse pressuposto, verifica-se que houve uma flutuação importante das taxas de desemprego no município entre 2000 e 2013, de 11,47\% em 2000, 5,37\% em 2010, retornando a 11,40\% em 2013 (Censo, 2010).

Quando consideradas as taxas de ocupação ${ }^{3}$ por grupos de idade, é possível identificar que o município se encontra fora da média do estado de Goiás em todas as faixas de idade. Os jovens de 15 a 29 anos possuem os indicadores com as maiores diferenças. Destaca-se que a taxa de ocupação relaciona a população remunerada por algum tipo de trabalho, incluindo a condição de informalidade.

O dado também acena para a relação entre empregabilidade, renda e nível de qualificação profissional. O município, apesar de não fugir à realidade estadual e nacional, apresenta elevadas taxas de analfabetismo, condição que apresenta grande

\section{QUADRO 1}

NÍVEL DE OCUPAÇÃO DAS PESSOAS

DE 10 ANOS OU MAIS DE IDADE - 2010 (EM \%)

\begin{tabular}{|c|c|c|c|c|c|c|c|c|c|c|c|c|c|c|c|c|}
\hline \multicolumn{17}{|c|}{ Grupos de idade } \\
\hline & Total & $10-13$ & 14 & 15 & $16-17$ & $18-19$ & $20-24$ & $25-29$ & $30-34$ & $35-39$ & $40-44$ & $45-49$ & $50-54$ & $55-59$ & $60-69$ & $>70$ \\
\hline $\begin{array}{l}\text { Águas } \\
\text { Lindas de } \\
\text { Goiás }\end{array}$ & 55,7 & 4,6 & 7,6 & 16,2 & 26,9 & 49,4 & 65,9 & 71,1 & 76,3 & 76,2 & 76,4 & 72,5 & 68,3 & 58,6 & 37,3 & 16,0 \\
\hline Goiás & 58,2 & 5,5 & 13,5 & 20,0 & 34,3 & 53,7 & 68,3 & 75,4 & 77,5 & 78,5 & 77,3 & 75,1 & 69,3 & 59,9 & 39,5 & 15,3 \\
\hline $\begin{array}{l}\text { Distrito } \\
\text { Federal }\end{array}$ & 59,1 & 2,8 & 5,5 & 8,3 & 22,0 & 43,4 & 65,6 & 76,7 & 79,7 & 80,6 & 80,1 & 78,4 & 72,9 & 60,6 & 39,3 & 14,6 \\
\hline
\end{tabular}


QUADRO 2

TAXA DE ANALFABETISMO.

PESSOAS DE 15 ANOS OU MAIS DE IDADE - 2010

\begin{tabular}{|c|c|c|c|c|c|c|c|c|c|c|}
\hline \multicolumn{11}{|c|}{ Grupos de idade } \\
\hline & \multicolumn{2}{|c|}{15 ou $>$} & \multicolumn{2}{|c|}{$15-24$} & \multicolumn{2}{|l|}{$25-39$} & \multicolumn{2}{|c|}{$40-59$} & \multicolumn{2}{|c|}{60 ou $>$} \\
\hline & Total & (\%) & Total & (\%) & Total & $(\%)$ & Total & (\%) & Total & (\%) \\
\hline Águas Lindas de Goiás & 7.613 & 7,0 & 442 & 1,4 & 1.797 & 4,0 & 3,238 & 12,0 & 2.136 & 35,0 \\
\hline Goiás & 362.829 & 8,0 & 12.821 & 1,2 & 52.479 & 3,4 & 131.052 & 9,7 & 166.477 & 30,0 \\
\hline Distrito Federal & 68.114 & 3,5 & 3.725 & 0,8 & 13.228 & 1,8 & 24.932 & 4,4 & 26.229 & 13,0 \\
\hline Brasil & 13.933 .173 & 9,6 & 851.062 & 2,5 & 2.623 .813 & 5,6 & 4.997 .340 & 11,6 & 5.460 .958 & 27,0 \\
\hline \multicolumn{11}{|c|}{ Branca } \\
\hline Águas Lindas de Goiás & 1.941 & 6,2 & 109 & 1,3 & 467 & 3,6 & 777 & 9,8 & 588 & 28,4 \\
\hline Goiás & 115.862 & 6,1 & 3.871 & 0,9 & 13.747 & 2,2 & 36.910 & 6,3 & 61.334 & 22,2 \\
\hline Distrito Federal & 19.807 & 2,4 & 1.208 & 0,7 & 3.371 & 1,1 & 6.485 & 2,6 & 8.743 & 8,4 \\
\hline Brasil & 4.166 .555 & 5,9 & 222.407 & 1,5 & 657.758 & 3,0 & 1.349 .706 & 6,1 & 1.836 .681 & 16,8 \\
\hline \multicolumn{11}{|c|}{ Preta } \\
\hline Águas Lindas de Goiás & 1.059 & 9,6 & 63 & 2,3 & 215 & 4,7 & 477 & 16,2 & 304 & 45,3 \\
\hline Goiás & 44.837 & 13,8 & 1.360 & 1,9 & 6.956 & 6,0 & 17.382 & 18,0 & 19.139 & 48,1 \\
\hline Distrito Federal & 9.319 & 5,6 & 397 & 1,0 & 1.869 & 2,9 & 3.678 & 7,8 & 3.375 & 24,0 \\
\hline Brasil & 1.702 .859 & 14,4 & 90.180 & 3,4 & 307.791 & 7,7 & 639.472 & 17,8 & 665.416 & 41,5 \\
\hline
\end{tabular}

Fonte: Censo, 2010.

importância quando comparada à realidade do município com o estado de Goiás e o Distrito Federal. Observa-se ainda relevantes diferenças nas taxas de analfabetismo entre jovens brancos e pretos em Águas Lindas de Goiás. A taxa de analfabetismo entre os jovens pretos de 15 e 25 anos é o dobro daquela dos jovens brancos na mesma faixa etária.

Assim, o cenário de violência vislumbra a relação entre a qualificação profissional, os níveis de escolaridade e os indicadores de desemprego como atributos importantes para a definição das políticas de enfrentamento do cenário violento. Essa relação já foi apontada por Daniel Cerqueira e Rodrigo Moura (2015) ao analisarem os níveis de violência homicida. Os autores consideram o estudo de Richard Freeman e Joel Rodgers (1999) realizado nos Estados Unidos, para comprovação da relação entre o acesso ao emprego e a renda sobre a taxa de homicídios em municípios brasileiros.

Os resultados apontam para um vínculo sólido entre o nível de empregabilidade dos municípios e os indicadores de homicídios. Apesar disso, o estudo mostra que a mesma relação não pode ser realizada quanto à renda do trabalho, aspecto que, segundo os autores, não trouxe impacto nos indicadores de homicídio. 
A população do município de Águas Lindas de Goiás está inserida em um circuito de trabalho e de consumo restrito, o que se reproduz na rede de serviços e emprego e define a organização social e econômica do município. A qualificação da mão de obra apresenta-se como ponto sensível, já que o município conta com apenas uma instituição de ensino superior particular. No sentido de romper com essa realidade, em abril de 2013, tiveram início as atividades do Instituto Federal de Goiás (IFG), com a oferta de cursos técnicos na área da saúde. O município não possui hospitais públicos ou privados e conta com apenas uma delegacia. Esses dados apontam para uma realidade, no que diz respeito à infraestrutura urbana, que não acompanhou o processo de expansão da cidade. Tal cenário não se restringe à oferta de oportunidades de emprego e renda, mas ainda à oferta, ao acesso e à qualidade de serviços públicos de maneira geral.

Com relação à urbanização do município, observa-se que a construção da rodovia BR-070 - que liga Brasília ao Mato Grosso (MT) -, teve impacto na configuração socioespacial do município. Anteriormente conhecido como Parque da Barragem, a cidade de Águas Lindas era formada por chácaras de recreio localizadas à margem da barragem do Descoberto, com pouca atividade agrícola e baixa densidade populacional. Com a construção da rodovia, entre os anos de 1970 e 1980, o acesso à área foi facilitado. Com a expansão urbana de Brasília e o elevado preço da terra urbana, a proximidade do município passou a provocar importantes movimentos de especulações imobiliárias, como indica Francisca Monteiro:

\footnotetext{
À medida que o tempo foi passando, muitas destas fazendas foram vendidas para a imobiliária Marajó e loteadas, no entanto, altos preços cobrados não permitiam as pessoas de baixo poder aquisitivo comprá-los, o que favoreceu o processo de ocupações informais, uma vez que algumas dessas fazendas encontravam-se praticamente abandonadas. As ocupações e loteamentos se tornaram comuns durante o processo de formação do município, com a chegada de imigrantes vindos, majoritariamente, do Distrito Federal, iniciou-se a ocupação dos espaços próximos a rodovia BR-070, ainda na década de 1980 (Monteiro, 2011: 3).
}

O município apresenta fortes características de cidade periférica que sofre com intensos fluxos migratórios e a falta de monitoramento por parte do poder público da ocupação do solo urbano. A paisagem urbana, na última década, vem sendo transformada rapidamente, o que tem gerado conflitos envolvendo o acesso e o controle do solo urbano, fato que se reflete em uma ocupação desordenada e precária de bairros que se encontram na periferia do município. Em 2010, 83,18\% das residências do município foram classificadas como semiadequadas ou inadequadas (Censo, 2010). 
Maria das Dores Nóbrega (2009) revela que o processo de ocupação irregular marca o acesso ao espaço urbano no município e as consequências envolvem desde aspectos ambientais, como a ocupação inadequada das áreas de proteção ambiental (APA $)^{4}$, até a própria organização social, com precarização da vida da população que vive em bairros sem qualquer infraestrutura básica. A fragilidade de estratégias para o ordenamento territorial, por exemplo, a partir de um plano de uso, ocupação e ordenamento do espaço urbano contribuíram para a configuração de conflitos de ordem socioambiental, envolvendo os agentes especuladores, a população e o poder público. Essa realidade pode ser identificada quando Nóbrega (2009) aponta que o saneamento básico é de responsabilidade dos moradores, com a construção de fossas, além da coleta de lixo que, naquele momento, ainda era realizada de maneira precária em caminhões comuns.

\section{As migrações e a expansão urbana}

Ao considerar o ranking do estado de Goiás, o município de Águas Lindas de Goiás ocupou a 5a posição, com um crescimento demográfico na última década, de 4,2\% (Segplan, 2010). Um aspecto que reforça esse dado foi analisado por Eguimar Chaveiro e Gilmar Silva (2012), a indicar que as taxas de crescimento demográfico não se vinculam ao aumento da natalidade, já que a taxa de fecundidade das mulheres no estado de Goiás é de 1,84 filhos por mulher, número abaixo das médias brasileira e do Centro-Oeste, que são de 1,94\% e 1,93\% respectivamente.

TABELA 2

MIGRAÇÕES INTRAMETROPOLITANAS

NA ÁREA METROPOLITANA DE BRASÍLIA

\begin{tabular}{|l|r|r|r|r|r|}
\hline \multirow{2}{*}{\multicolumn{1}{|c|}{ Cidade }} & \multicolumn{5}{|c|}{ Percentual da Residência Anterior } \\
\cline { 2 - 6 } & BA & MG & RJ & SP & DF \\
\hline Água Fria de Goiás & 11,2 & 7,2 & 0,4 & 1,7 & 34,0 \\
\hline Águas Lindas de Goiás & 4,2 & 2,1 & 0,3 & 1,4 & 75,9 \\
\hline Cidade Ocidental & 5,7 & 3,4 & 1,5 & 2,7 & 62,7 \\
\hline Luziânia & 5,8 & 6,7 & 0,5 & 1,8 & 56,8 \\
\hline Novo Gama & 4,8 & 3,7 & 0,6 & 1,6 & 60,1 \\
\hline Padre Bernardo & 4,2 & 4,9 & 0,0 & 0,7 & 72,4 \\
\hline Planaltina de Goiás & 8,3 & 5,2 & 0,3 & 1,7 & 56,2 \\
\hline Santo Antônio do Descoberto & 5,4 & 3,9 & 0,6 & 1,9 & 57,5 \\
\hline Valparaíso de Goiás & 5,6 & 5,1 & 2,1 & 1,9 & 56,5 \\
\hline Total & 5,4 & 4,3 & 0,8 & 1,7 & 63,7 \\
\hline Fonte: Chaveiro \& Silva (2012). & & & & & \\
\hline
\end{tabular}


Os dados dos últimos 20 anos revelam que o estado de Goiás é um importante polo de atração populacional no país, sendo que os municípios goianos que integram a Ride-DF e encontram-se mais próximos do Distrito Federal foram os que apresentaram as taxas mais elevadas de migração. Apesar de os recentes estudos apontarem uma redução no ritmo da migração, esse movimento ainda se mantém, conforme apontam os dados da Codeplan (2013) sobre os fluxos migratórios que envolvem o Distrito Federal e o Entorno.

Para Maria Célia Caiado (2005), a migração intrametropolitana também é responsável pela redefinição da malha urbana na Ride-DF, fato desencadeado com a não absorção dos migrantes das diversas regiões do país, especialmente da região Nordeste, notadamente dos estados da Bahia, do Piauí, do Maranhão e do Ceará. Segundo a autora, a região Nordeste contribuiu com 95,1\% da população que migrou para o Entorno entre 1970 e 1980, fluxo que foi reduzido para 41,5\% de 1990 a 2000, representando um total de 153.363 pessoas entre 1990 e 2000. Águas Lindas de Goiás recebeu o maior fluxo intrametropolitano, mais de 33 mil habitantes (Caiado, 2005: 73).

O Distrito Federal seria reconhecido "como lugar de passagem dos migrantes, um Trampolim Demográfico para a população que reside nos municípios goianos próximos ao Distrito Federal" (Chaveiro \& Silva, 2012: 199). Essa realidade, quando analisada na escala da Ride-DF, torna a questão das migrações mais evidente, pois grande parte dos municípios tem uma população não natural.

O conflito permeia a constituição espacial e social do Entorno do Distrito Federal, desde o uso do espaço até as necessidades de sobrevivência em meio à diversidade de valores e de demandas sociais. Do ponto de vista da identidade cultural, Eguimar Chaveiro e Gilmar Silva apontam o desencadeamento de

situações adversas no que concerne à identidade local e regional, na medida em que desorganiza relações historicamente estabelecidas e desagrega valores que auxiliam na identificação e na distinção do "eu", do "outro" e do "nós" no tempo e no espaço (Chaveiro \& Silva, 2012: 203).

A seguir, serão analisados os homicídios no município de Águas Lindas de Goiás, durante o ano de 2010. 


\section{Águas Lindas de Goiás: homicídios em 2010}

O município de Águas Lindas de Goiás está em terceiro lugar no ranking dos municípios que apresentaram as maiores taxas de homicídios em 2010.

A análise das ocorrências de homicídios realizada por Costa et alii (2014) aponta tendências comuns dos homicídios nos diversos municípios, em variáveis tais como distribuição no mês, local da ocorrência, perfil da vítima e meio empregado. A seguir, apontamos essas tendências gerais que também caracterizam a ocorrência dos homicídios no município de Águas Lindas de Goiás.

Segundo o estudo de Costa et alii (2014), a ocorrência dos homicídios não apresenta sazonalidade, o que significa que as ocorrências se distribuem aleatoriamente durante o ano. Mas, os dias sábado e domingo concentram o maior número de homicídios. Águas Lindas de Goiás é uma cidade dormitório, produto do processo de metropolização com segregação socioespacial e exclusão social de Brasília, aspectos já abordados neste artigo. Lembre-se ainda que mais de 30 mil habitantes declararam trabalhar no Distrito Federal em ocupações com baixa qualificação profissional e remuneração. Em função do movimento pendular da população, durante a semana a cidade permanece bastante deserta, concentrando grande fluxo de pessoas aos finais de semana, quando os trabalhadores aproveitam para realizar compras, procurar atividades de lazer em lugares públicos, como bares, festas, reunir-se nas residências de familiares e amigos e participar de cultos religiosos.

TABELA 3

HOMICÍDIOS EM MUNICÍPIOS DA

REGIÃO INTEGRADA DE DESENVOLVIMENTO

DO DISTRITO FEDERAL E ENTORNo (RIDE-DF) - 2010

\begin{tabular}{|l|c|c|c|}
\hline \multicolumn{1}{|c|}{ Municípios } & Homicídios & $\%$ & \% Acumulada \\
\hline Luziânia & 145 & 25,6 & 25,6 \\
\hline Valparaíso de Goiás & 114 & 20,1 & 45,8 \\
\hline Águas Lindas de Goiás & 101 & 17,8 & 63,6 \\
\hline Novo Gama & 76 & 13,4 & 77,0 \\
\hline Formosa & 38 & 6,7 & 83,7 \\
\hline Planaltina de Goiás & 33 & 5,8 & 89,6 \\
\hline Sto. Antônio do Descoberto & 30 & 5,3 & 94,9 \\
\hline Cidade Ocidental & 29 & 5,1 & 100,0 \\
\hline Total & 566 & 100,0 & \\
\hline Fonte: Secretaria de Segurança Pública (SSP/GO). & & \\
\hline
\end{tabular}


5. Os locais de ocorrência foram classificados pela Polícia Civil de Goiás como: via pública, residência, estabelecimento comercial, local ermo, unidade hospitalar, unidade prisional e outros.
Verificou-se que o horário de maior concentração de ocorrências policiais é entre seis da tarde e seis da manhã, com maior concentração dessas ocorrências na madrugada, entre uma e seis horas. Quase 60\% dos homicídios acontecem em vias públicas. Também é significativo o número de homicídios em residências (19\%), o que pode indicar a recorrência de conflitos interpessoais entre familiares ou conhecidos ${ }^{5}$ que afloram nos encontros de final de semana. Em estabelecimentos comerciais - como bares ocorrem $11 \%$ dos homicídios. Os dados apontam para as relações e interações entre as vítimas e os agentes dos homicídios. Essas ocorrências sobrevêm em municípios específicos da Ride-DF, notadamente em bairros pobres, muito precários e de formação recente, envolvendo fundamentalmente os jovens, como será discutido abaixo, o que revela a influência de aspectos estruturais na ocorrência dos homicídios.

A análise do perfil das vítimas de homicídio do conjunto dos municípios da Ride-DF apresentada por Costa et alii (2014) revelou que são do sexo masculino em 94\% dos registros. Com relação à idade, a faixa etária prevalecente situa-se entre 18 e 25 anos em $16 \%$ dos eventos registrados, considerando que, em $61 \%$ dos casos, não houve o dado referente ao registro de idade. Esta tendência repete-se na análise desagregada por município. Este perfil de vítimas de homicídio apontado pelos autores no caso dos municípios integrantes da Ride-DF se repete no Brasil. O Mapa da violência III (Waiselfisz, 2002) mostra que os jovens pobres são tanto agentes como vítimas dos homicídios.

De acordo com os dados da Secretaria de Segurança Pública de Goiás (SSP/GO) (2013), o principal meio empregado para os homicídios são as armas de fogo, seguido de facas. Em 75\% das ocorrências, há registro de "perfuração por arma de fogo" e, em 15\%, "facada no abdômen". A presença de armas na periferia aponta para diversas ilegalidades.

A pesquisa em Águas Lindas de Goiás junto aos atores da segurança pública e do Serviço de Assistência Social também apontou para a presença de álcool nas ocorrências de homicídios.

Ao analisar a distribuição espacial do conjunto dos municípios, observa-se que além de estarem sob influência do Distrito Federal e serem oficialmente conside- 
rados urbanos, contam com extensas áreas rurais que se comunicam com os centros urbanos através das trajetórias de mobilidade cotidiana de seus habitantes, em função do emprego ou do trabalho, dos estudos, do consumo etc. Criam-se assim espaços de transição entre o rural e o urbano com seus desafios específicos, situação que exige a superação da tradicional dicotomia urbano-rural na análise dos processos sociais que caracterizam a metropolização das cidades.

Esta característica é também marcante no caso do município de Águas Lindas de Goiás, o que permite imaginar tensões e conflitos gerados nos processos de interpenetração entre os mundos rural e urbano. Essa hipótese explicativa da frequência dos homicídios precisa ser melhor explorada em um próximo estudo. Contudo, considera-se necessário apontar que esses processos de interpenetração produzem híbridos de objetos, relações e significados, que podem ajudar na compreensão das tensões e dos conflitos por detrás da violência homicida na Ride-DF (ver Malheiro, 2009).

A Secretaria de Segurança Pública de Goiás registrou ocorrência de homicídio em 195 bairros dos municípios da Ride-DF. Ao analisarem a distribuição espacial desses homicídios, Costa et alii (2013) verificaram que 23 bairros concentraram 50,1\% dos homicídios. No caso do município de Águas Lindas de Goiás, bairros de formação recente concentram as ocorrências de homicídios em 2010. Sete bairros responderam por mais da metade das mortes violentas, mais precisamente por $52,5 \%$ das ocorrências de homicídios registradas em 2010. São estes os bairros: Jardim Barragem (26,7\%), Jardim Águas Lindas II (5,9\%), Camping Club (5,0\%), Cidade do Entorno (5,0\%), Setor Coimbra (4,0\%), Girassol (3,0\%), e Jardim América (3,0\%).

Em síntese, o conceito de cidade dormitório, que definimos aqui em função do movimento pendular da população do município em direção ao Distrito Federal, revela um número significativo de moradores de Águas Lindas de Goiás trabalhando ou estudando no Distrito Federal, razão pela qual, como já observado, há um número maior de pessoas no município aos finais de semana, quando é possível para os habitantes resolverem seus conflitos e quando de fato acontecem a maior parte dos homicídios.

O município é produto do processo de metropolização, caracterizado pela segregação socioespacial e a exclusão social que dá lugar à expansão da cidade através da ocupação informal do solo e da moradia por migrantes intrametropolitanos e também migrantes de outros estados. Estes movimentos migratórios apontam para a ausência de coesão entre os habitantes dos novos bairros precários que se configuram, a proliferação de choques culturais em função dos valores e costumes diversos dos habitantes, a ausência de serviços básicos, os conflitos em torno da ocupação 
do solo, do abastecimento de água e eletricidade para as residências, o que gera conexões clandestinas e disputas que podem acirrar os conflitos interpessoais.

Os padrões sociais de desigualdade residencial observados em Águas Lindas sugerem que a exclusão e o isolamento social e a concentração socioespacial dos desfavorecidos, reforçados por uma baixa capacidade institucional de gestão das estruturas e serviços públicos da cidade, atuam como forças que prejudicam sua organização social e, portanto, dificultam a comunicação e a capacidade das autoridades públicas, e também da comunidade, para o controle social da violência.

O fato de as ocorrências de homicídio se distribuírem aleatoriamente durante o ano, considerando mesmo o maior número de homicídios aos sábados e domingos, indica que o baixo grau de organização social e a criminalidade devem ser tratados como resultado das características da cidade em geral, e de suas comunidades violentas em particular. Pesquisas adicionais são necessárias para corroborar esta hipótese.

As características das ocorrências de homicídio, com maior frequência entre uma e seis da manhã, aos sábados e domingos; $60 \%$ em vias públicas; o número de homicídios em residências (19\%); bem como os homicídios em bares e similares que representam $11 \%$ do total são dados que reforçam a incidência de conflitos interpessoais entre familiares ou conhecidos nos finais de semana. Pode-se sugerir que a situação de baixa organização social não só priva as comunidades de recursos como precariza a mobilização para controlar o crime, uma vez que aumenta o isolamento social entre os moradores, o que impede a comunicação e interfere em sua capacidade de perseguir valores comuns. Ao mesmo tempo, uma ordem cultural orientada por essa situação de baixa organização social é marcada pela carência de oportunidades convencionais para o avanço da mobilidade social e de status. Assim, em busca por rotas alternativas, abraçar valores não convencionais pode incluir atos infracionais e a própria criminalidade.

A hipótese da situação de baixa organização social nos bairros de formação recente sugere Águas Lindas de Goiás como um exemplo empírico. Essa situação aparece moldando valores e comportamentos dos residentes, por exemplo, encorajando atitudes de disputas e sanções agressivas contra indivíduos que mostram desrespeito. A cultura de rua fornece uma "lógica permitindo que aqueles que estão inclinados à agressão precipitem tensões e encontros violentos de uma forma aprovada", normativa (Anderson, 1999: 33). Um segmento da comunidade permanece apegado a valores convencionais, enquanto outro segmento abraça a cultura de rua. Em termos mais gerais, as condições estruturais e as respostas subculturais e normativas moldam o crime nos bairros. Os dados apresentados sobre as ocorrências de homi- 
cídio nos bairros de formação recente, em 2010, mostraram que estes representavam $52,5 \%$ dos registros. Então, é razoável dizer que, em alguma medida, os efeitos de uma situação de baixa organização social podem ter um impacto direto significativo nas taxas de homicídios em Águas Lindas.

O perfil das vítimas de homicídios - homens e jovens - coloca uma questão relacionada com as características da comunidade, ou a coincidência ou similaridade das ocorrências e localização. Os dados espaciais permitem inferir que a baixa organização social de Águas Lindas de Goiás tem efeitos sobre a qualidade de vida de um bairro, e como isso influencia o crime. Uma consequência é a emigração de residentes com recursos suficientes para mudar, deixando para trás os moradores mais desfavorecidos, interrompendo redes sociais preexistentes e a capacidade de controle informal pela comunidade.

A seguir são analisados alguns aspectos que revelam as características da gestão da segurança pública no município de Águas Lindas de Goiás e da rede de prevenção da violência.

\section{Gestão da segurança pública e rede de prevenção da violência}

As configurações das agências governamentais de prevenção ao crime e segurança pública envolvem a administração, a criação e a manipulação do ambiente circundante de modo sistemático e permanente. Assim, a existência de políticas urbanas, de segurança pública e setoriais, de programas assistenciais e de atividades agregadoras e gerenciais podem servir como indicadores das características sociais e organizacionais dos municípios da Ride-DF.

A seguir, são analisadas essas instâncias para o conjunto dos municípios, destacando, sempre que possível, a situação específica do município de Águas Lindas de Goiás, com base na Pesquisa de Informações Básicas Municipais (Munic), realizada pelo IBGE (2012). Iniciamos a análise observando a presença dos conselhos municipais, considerados um instrumento institucional na gestão de políticas públicas para a sua efetiva atuação, permitindo uma maior transparência à gestão dos recursos em políticas públicas locais, pois os conselhos descentralizam as ações a fim de estabelecer um novo padrão de políticas sociais (IBGE, 2012).

Os dados do IBGE (2012) indicam a existência de conselhos municipais e apontam para a relativa institucionalização desses conselhos e, de forma geral, a fragilidade na participação de segmentos da sociedade civil na globalidade dos processos de elaboração da política pública. Particularmente na segurança pública, apenas três 
6. Observa-se baixa implementação destes conselhos nos outros municípios.

7. Dentre os oito municípios em análise, apenas a Cidade Ocidental oferece o serviço de atendimento telefônico ao público, e $50 \%$ do conjunto de municipalidades oferecem serviço de postal e jornais.

8. Recentemente, o Senado Federal aprovou o estatuto que garante poder de polícia às Guardas Municipais (PLC 39/2014). municípios constituíram conselhos para a elaboração de políticas locais, um deles é o de Águas Lindas de Goiás.

Por outro lado, destaca-se que a totalidade dos municípios fundaram seus conseIhos de assistência social, sugerindo essa área como prioritária devido a uma grande vulnerabilidade social. Águas Lindas de Goiás também declara ter constituído seu conselho de segurança pública, o que pode indicar o reconhecimento e a valorização por parte do poder público local de processos dialógicos entre os atores sociais envolvidos na formulação e implementação de políticas públicas na área6.

Na esfera institucional - da infraestrutura de comunicação da população com o poder público local -, Águas Lindas de Goiás não conta com uma estrutura adequada, contando tão só com um site/portal, o que pode sugerir menor participação e menor número de interações dos cidadãos quanto aos seus diversos interesses ${ }^{7}$.

O trabalho da Guarda Municipal é associado ao controle de fatores situacionais do crime, na vigilância dos espaços públicos e potenciais alvos como vias públicas com estabelecimentos comerciais, estacionamentos etc. São ações de ronda escolar, posto de guarda a patrulhamento de vias públicas, todas ações de prevenção dentro de uma perspectiva de defesa territorial dos espaços públicos. As ações de auxílio à Polícia Civil, ao Conselho Tutelar, no ordenamento do trânsito indicam uma interação operacional ativa e segmentada, consolidando o poder de polícia administrativa à Guarda Municipal ${ }^{8}$. O município de Águas Lindas de Goiás não conta com a Guarda Municipal, nem com o patrulhamento das vias públicas. Lembre-se que a maior parte dos homicídios acontece nas vias públicas aos finais de semana.

A situação dos equipamentos de segurança pública pode ser analisada considerando a oferta ou não de estruturas especializadas no combate ao crime e de investigação criminal. A existência ou não de delegacias especializadas pode mostrar maior ou menor atenção para certos crimes dentro do município, e refletir as incapacidades da estrutura social local e a eficácia das ações de prevenção. Os recursos de segurança pública nos municípios estão concentrados nas delegacias distritais, com exceção para a Delegacia de Atendimento à Mulher, presente em seis municípios.

Com efeito, o município de Águas Lindas de Goiás declara ter Delegacia Especializada no Atendimento à Mulher. Contudo, a pesquisa de campo indicou que essa delegacia não existe. Ao observar o quadro anual de criminalidade no município entre janeiro e dezembro de 2012, segundo dados da SSP/GO, foram registrados 30 estupros. Entre janeiro e outubro de 2013 foram registrados 31 estupros. É um número de denúncias elevado e mais ainda se considerarmos a ausência de uma Delegacia 
Especializada de Atendimento à Mulher. O município de Águas Lindas de Goiás também não conta com uma Delegacia de Proteção à Criança e ao Adolescente.

A vulnerabilidade social da população e a exigência legal de políticas setoriais na área da assistência social ajudam a entender a maior consolidação dessas políticas em relação à segurança pública nos municípios da Área Metropolitana de Brasília. Dessa forma, com exceção dos serviços para crianças entre 0 a 6 anos, a quase totalidade dos municípios conta com políticas de proteção básica em especial para famílias e/ou indivíduos em situações de risco pessoal e social.

A ausência de serviços para crianças de 0 a 6 anos deve ser entendida como um fator que influencia o ambiente em que as crianças crescem, se desenvolvem e se integram socialmente. Se tais tipos de serviços podem ser considerados na área da prevenção social e segurança pública, então é necessário desenvolver estratégias para influenciar o trabalho em conjunto com os serviços de família.

Todos os municípios contam com os serviços de Medida Socioeducativa de Liberdade Assistida e de Prestação de Serviços à Comunidade. Pode-se entender esses serviços como ações de prevenção situacional do crime, uma vez que as medidas socioeducativas apontam a tangibilidade da punição.

Por último, a pesquisa de campo apontou que, em Águas Lindas de Goiás, 70\% dos funcionários da assistência social não têm vínculo de trabalho permanente. Em síntese, o município de Águas Lindas de Goiás apresenta precária estrutura e organização da segurança pública, agravada pela ausência de Guarda Municipal, delegacias especializadas etc., assim como pela existência muito mais formal que real de uma rede de assistência social satisfatória.

\section{Conclusões}

Qual a realidade do município de Águas Lindas de Goiás?

Trata-se de um município que depende do ponto de vista do trabalho/emprego, educação, saúde etc. do Distrito Federal. É resultado do processo de metropolização de Brasília, caracterizado por segregar espacialmente a população e excluí-la socialmente. As migrações intrametropolitanas indicam o êxodo permanente das pessoas para além do Distrito Federal, na fronteira com o estado de Goiás, devido, em grande parte, à especulação imobiliária no Distrito Federal que impacta nas possibilidades de sobrevivência dos trabalhadores e trabalhadoras menos favorecidos e os obriga a essa migração, cada vez mais distante das oportunidades de trabalho/ emprego, e dos serviços básicos existentes. 
As informações analisadas apontam para as condições adversas de vida no município. Observou-se que os homicídios acontecem com maior incidência nos bairros de formação recente, produto da expansão desordenada da cidade que se dá a partir das ocupações informais das terras. Estes processos sociais atraem também migrantes extrametropolitanos que criam novos padrões de convivência e de lazer que podem gerar tensões e conflitos, notadamente enfrentados com o uso da violência. Agrega-se a esta situação os déficits identificados na estrutura e na organização da segurança pública e dos programas sociais.

A governança metropolitana permite a articulação de agentes públicos e privados na consolidação dos serviços públicos de interesse comum para a ação no território. Uma função de interesse comum necessita de estratégias de articulação com diferentes agentes públicos e privados para a eficiência da prestação do serviço. É necessário compatibilizar ofertas de emprego, dinâmica econômica e local de residência da população, de modo a minimizar as diferenças de oportunidades entre municípios periféricos e nucleares de áreas metropolitanas.

No Distrito Federal, a cooperação ganha um nível de complexidade maior do que em qualquer outro local. O partilhamento de competências envolve os estados e o Distrito Federal, articulação interestadual e interfederativa. Embora seja reconhecida a necessidade de governança metropolitana na segurança pública, há desafios em relação às formas de cooperação, às atribuições dos papéis e às instâncias a serem criadas para dirimir os conflitos entre as instituições.

Abstract: This work brings out the metropolitan context of homicides in Brasilia, in 2010, specifically the town of Aguas Lindas de Goias. The paper highlights some features of the Brasilia metropolitan area, that interfaces with the structure and organization of public security, the deficit of health care activities in the municipality and also the dynamics of homicides. The research work was carried out on secondary socioeconomic data and semi-structured interviews with the actors involved with development of public safety and welfare programmes and policies. The results indicate to the socio-spatial segregation and social exclusion as the core features of the process of metropolization of the Brasilia. The high level of economic dependence and social interaction, between Aguas Lindas de Goias and Brasilia, is demonstrated throughout the offering of vacancies within the Brasilia's labor market and basic health services. In this context, and considering the high rate of homicides in the town, the paper indicates the need for cooperative policies between the different level of government involved (federal, state and municipalities) in economic and social sectors and public safety policies.

Keywords: metropolises, public security, murder, socio-spatial segregation. 


\section{Referências}

ABRAMOWAY, Ricardo et alii. Juventude, violência e vulnerabilidade social na América Latina: desafios para políticas públicas. Brasília: Unesco, 2002.

ANDERSON, Elijah. Codes of street. New York: Norton, 1999.

ANDRADE, Luciana; MARINHO, Antônio Couto. Organização social do território e violência letal na Região Metropolitana de Belo Horizonte: o balanço de uma década. In: ANDRADE, Luciana; SOUZA, Dalva; FREIRE, Flávio Henrique (Orgs.). Homicídios nas regiões metropolitanas. Rio de Janeiro: Letra Capital, 2013.

. Explorando as relações entre metrópole, juventude e homicídios. e-metropolis: Revista Eletrônica de Estudos Urbanos e Regionais, v. 1, p. 13-21, 2011.

ATLAS DO DESENVOLVIMENTO HUMANO NO BRASIL. Brasília: Programa das Nações Unidas para o Desenvolvimento (Pnud); Instituto de Pesquisa Econômica Aplicada (Ipea); Fundação João Pinheiro (FJP), 2013.

CAIADO, Maria Célia Silva. Deslocamentos intra-urbanos e estruturação socioespacial na metrópole brasiliense. São Paulo em Perspectiva, v. 19, n. 4, p. 64-77, Out.-Dez. 2005.

CERQUEIRA, Daniel; MOURA, Rodrigo Leandro. O efeito das oportunidades no mercado de trabalho sobre as taxas de homicídios no Brasil. Anais do Encontro Associação Nacional dos Centros de Pós-Graduação em Economia. Florianópolis (SC), 2015.

CHAVEIRO, Eguimar Felício; SILVA, Gilmar Elias Rodrigues. Valparaíso de Goiás, a formação de um município de migrantes no contexto do Distrito Federal. Boletim Goiano de Geografia, v. 32, n. 2, Jul.-Dez. 2012. Disponível em: <http://www.revistas.ufg.br/index.php/bgg/article/view/21086>.

COMPANHIA DE PLANEJAMENTO DO DISTRITO FEDERAL (CODEPLAN). Brasillia e sua região polarizada. Brasília: Codeplan, 2013.

COSTA, Arthur; SORIA BATISTA, Analía ; MACHADO AMARAL, Bruno; SACKSESKI, Cristina. Avaliação dos homicídios na Área Metropolitana de Brasília. Brasília: Coleção Segurança com Cidadania, 2014.

CRUZ, Marcus Vinicius Gonçalves da; BATITUCCI, Eduardo (Orgs). Homicídios no Brasil. Rio de Janeiro: Editora FGV, 2007.

FAUSTO, Boris. Crime e cotidiano. A criminalidade em São Paulo 1880-1924. São Paulo: Brasiliense, 1984. 
FREEMAN, Richard B.; ROGERS, Joel. What workers want. Ithaca (NY): Cornell University Press, 1999.

FUNDAÇÃO JOÃO PINHEIRO. Déficit habitacional do Brasil. Belo Horizonte: Fundação João Pinheiro, 2013.

INSTITUTO BRASILEIRO DE GEOGRAFIA E ESTATÍ́STICA (IBGE). Informações Básicas Municipais (Munic). Rio de Janeiro: IBGE, 2012.

Produto Interno Bruto dos municípios. Rio de Janeiro: IBGE, 2010.

MALHEIRO, Bruno Cezar P. Entre rio, rodovias e grandes projetos: mudanças e permanências em realidades urbanas no Baixo Tocantins (PA). In: TRINDADE JR., Saint Clarie et alii (Orgs.). Pequenas e médias cidades na Amazônia, p. 59-91. Belém: Fase: ICSA-UFPA, Observatório Comova, 2009.

MARINHO, Antônio Couto; BASEGIO, Leandro José. Homicídios e relações municipais metropolitanas na Região Metropolitana de Porto Alegre. In: ANDRADE, Luciana; SOUZA, Dalva; FREIRE, Flávio Henrique (Orgs.). Homicídios nas regiões metropolitanas. Rio de Janeiro: Letra Capital, 2013.

MIRAGLIA, Paula. Cosmologias da violência: entre a regra e a exceção - Uma etnografia da desigualdade em São Paulo. "Série: Produção Acadêmica Premiada". São Paulo: FFLCH/USP, 2010.

MONTEIRO, Francisca das Chagas Sobrinho. Águas Lindas do Goiás: reinterpretando sua história por meio de imagens. Anais /l Congresso Internacional de História da UFG. Jataí (GO), 2011.

MORENOFF, Jefrey; SAMPSON, Robert; RAUDEMBUSH, Stephen. Neighborhood inequality, collective efficacy, and the spatial dynamics of urban violence. Criminology, v. 39, n. 3, p. 517-558, 2001.

MOURA, Rosa; GORSDORF, Leandro Franklin. Questão metropolitana. In: REZENDE, Sonaly Cristina (Org.). Panorama do saneamento básico no Brasil. Cadernos Temáticos, v. 3. Brasília: Ministério das Cidades; Secretaria Nacional de Saneamento Ambiental, 2011.

NÓBREGA, Maria das Dores Silva. Representações sociais da moradia e da natureza dos moradores de loteamentos de baixa renda em Águas Lindas de Goiás (GO). Dissertação (Mestrado em Geografia) - Departamento de Geografia, Universidade de Brasília. Brasília, 2009. 
SECRETARIA DE ESTADO DE GESTÃO E PLANEJAMENTO (SEGPLAN), INSTITUTO MARIO BORGES. Mobilidade pendular da população em Goiás. Estudos do IMB. Goiânia (GO), Out. 2012.

SECRETARIA DE SEGURANÇA PÚBLICA E ADMINISTRAÇÃO PENITENCIÁRIA DE GOIÁS. Dados sobre homicídios. Goiânia: SSPAPG, 2013.

—. Panorama da migração em Goiás. Estudos do IMB. Goiânia (GO), 2010.

SHAW, Clifford; MCKAY, Henry. Juvenile delinquency and urban areas - A study of rates of delinquency in relation to diferential characteristics of local communities in American cities. Chicago: The University of Chicago Press, 1972 [1942].

SORIA BATISTA, Analía; FRANCA, Karla; BERDET, Marcelo; BORTOLO, Marizangela, Gestão da segurança pública e metropolização: A Região Integrada de Desenvolvimento do Distrito Federal e Entorno (Ride-DF). Relatório de pesquisa, 2013.

SPOSITO, Maria Encarnação Beltrão. Novos conteúdos nas periferias urbanas das cidades médias do estado de São Paulo, Brasil. Investigaciones Geográficas - Bol. Inst. de Geografía, v. 54, p. 114-139, México, 2004.

WAISELFISZ, Julio Jacobo. Mapa da violencia. Mortes matadas por armas de fogo. Brasília: Secretaria-Geral da Presidência da República, 2013.

—. Mapa da violência nos municípios brasileiros. Brasília: Rede de Informação Tecnológica Latino-Americana (Ritla); Instituto Sangari; Ministério da Saúde, Ministério da Justiça, 2008.

. Mapa da violencia. Os jovens do Brasil. Brasília: Unesco; InstitutoAyrton Senna; Ministério da Justiça/SEDH, 2002. 
